\title{
Serum Vitamin D And Serum Ferritin Levels In Male Pattern Hair Loss :Is There A role?
}

\section{Samar M.R. El-Tahlawy (1), Mohammed A. Alkhayat (2),Hassan S.E. Ali (3)and Eman A.A. Samhoud(4).}

(1)professor of Dermatology, Dermatology department, Faculty of Medicine Cairo University.

(2)Assistant professor of Dermatology, andrology and STDs Faculty of Medicine Minya university.

(3)lecturer of Biochemistry, Faculty of Medicine Fayoum University.

(4)Department of Dermatology, $\mathrm{MOH}$.

Corresponding author: prof . Samar M.R. El-Tahlawy

E-mail address: raghaad100@gmail.com

Tel: 01129569294

\begin{abstract}
Male androgenetic alopecia is the most common cause of alopecia in men. The pathogenesis involves androgen-induced minaturisation of terminal hairs into vellus hairs in affected regions of the scalp. Some degree of follicular minaturisation and consequential hair loss is universal and is considered to be a physiological secondary sexual characteristic.

Various studies evaluated serum ferritin level and serum vitamin $\mathrm{d}$ levels in patients with alopecia. Most studies done on female patients with alopecia with very constracting results.Very few studies evaluated serum ferritin level and serum vitamin D levels in males with androgenetic alopecia, so we
\end{abstract}

tried to spot light in that issue. The aim of this study is to measure serum vitamin D and serum ferritin levels in patients with male pattern hair loss compared to control. This study was conducted in Dermatology Department of Fayoum University Hospital. 60 male subjects were included, 30 patients had androgenetic alopecia and 30 apparently healthy volunteers as control group. Our results show that vitamin D was statistically significantly lower in patients with androgenetic alopecia. While there was no statistically significant difference in Ferritin levels between both groups.

Keywords: androgenetic alopecia , Male pattern hair loss, Serum Ferritin, Vitamin D. 


\section{Introduction:}

Male androgenetic alopecia is the most common form of hair loss in men, affecting 30$50 \%$ of men by age of fifty years. Although male androgenetic alopecia is often regarded as a relatively minor dermatological condition, hair loss impacts self-image and is a great cause of anxiety and depression in some men [1].The key pathophysiological features of male androgenetic alopecia are alteration in hair cycle development, follicular miniaturization and inflammation. In male androgenetic alopecia, the anagen phase decreases with each cycle, while the length of telogen remains constant or is prolonged. Ultimately, anagen duration becomes so short that the growing hair fails to achieve sufficient length to reach the surface of the skin, leaving an empty follicular pore [2]. A caloric deprivation or deficiency of several macro and micronutrients, such as proteins, minerals, essential fatty acids, and vitamins, can lead to hair loss [3].

The most widely cited nutritional causes of hair loss include iron, one of the key micronutrients in metabolism of our body. From its diverse functions, it is well known that iron deficiency is associated with a lot of pathological conditions [2].

Since non-anemic iron deficiency was first suggested as an etiologic factor for diffuse hair loss, low iron stores have been considered a possible contributing factor in both conditions [4].
Assessment of serum ferritin levels is therefore generally recommended as part of the routine investigation, and dermatologists commonly prescribe iron supplementation in alopecia under the assumption that low iron stores may be causing hair loss. However, contradictory data have so far failed to support this practice[5].

Another player in the process of hair growth and wellness is vitamin D which may play role in hair follicle cycling [6]. One study of eighty females with telogen effluvium or female pattern hair loss showed that serum vitamin D levels were significantly lower than that in controls. Furthermore, vitamin D levels decreased with increased disease severity. However, data on the effects of vitamin D supplementation in hair loss is lacking [4].

Interestingly, several authors have pointed to the close relation that exists between the concentration of iron and the vitamin D level. Vitamin $\mathrm{D}$ is an inactive precursor, requiring two hydroxylation steps: in the liver then in the kidney to be converted to $1 \alpha, 25$ dihydroxyvitamin D3 (calcitriol), the active hormone [7].

\section{Patients And Methods}

This was a case-control study carried out at Dermatology department, faculty of medicine, Fayoum University. The study included 60 male subjects divided into 2 groups ( 30 male patients with androgenetic 
alopecia and 30 healthy age-matched male persons. All subjects included in this study were subjected to: Full history taking, clinical examination and measurement of serum ferritin and vitamin D levels.

\section{Results:}

1.This study revealed that The mean serum vitamin D level was $37.1 \mathrm{ng} / \mathrm{ml}$ in cases compared to 44.2 $\mathrm{ng} / \mathrm{ml}$ in control. Vitamin D level was statistically significantly lower in cases than control with $\mathrm{p}$ value $=$ 0.02

\begin{tabular}{|l|c|c|c|c|c|c|}
\hline & Mean & SD & Mean & SD & $\begin{array}{c}\text { p- } \\
\text { value }\end{array}$ & Sig. \\
\hline Vitamin D (ng/ml) & 44.2 & 9.6 & $\underline{\mathbf{3 7 . 1}}$ & 11.9 & $\mathbf{0 . 0 1}$ & $\mathbf{S}$ \\
\hline
\end{tabular}

Table (1): Comparisons of vitamin D level in study groups.

2. The mean serum ferritin level in cases was $75.7 \mathrm{ng} / \mathrm{ml}$ compared to $107.6 \mathrm{ng} / \mathrm{ml}$ in controls. There was no statistical significant difference between cases and controls as regards level of serum ferritin. with pvalue $=0.2$

\begin{tabular}{|c|c|c|c|c|c|c|}
\hline \multirow{2}{*}{ Variables } & \multicolumn{2}{|c|}{$\begin{array}{c}\text { Controls } \\
(n=30)\end{array}$} & \multicolumn{2}{c|}{$\begin{array}{c}\text { Cases } \\
(n=30)\end{array}$} & $\begin{array}{c}\text { p- } \\
\text { value }\end{array}$ & Sig. \\
\cline { 2 - 7 } & Mean & SD & Mean & SD & & \\
\hline \multirow{2}{*}{ Ferritin level (ng/ml) } & 107.6 & 92.8 & 75.7 & 79.6 & 0.2 & NS \\
\hline
\end{tabular}

Table (2): Comparisons of ferritin level in study groups. 


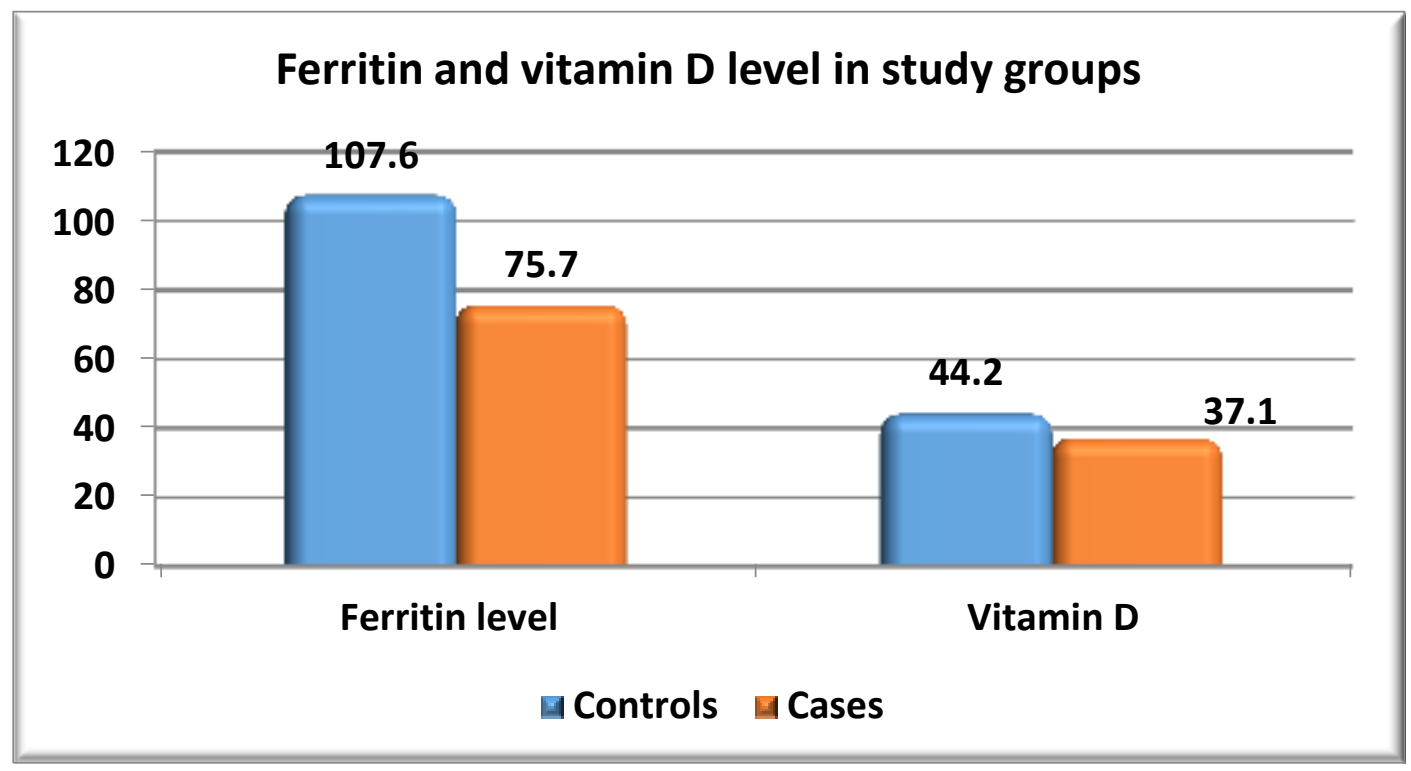

Figure (1): Comparison of vitamin D and ferritin levels between cases and control.

3. there was no statistical significant difference with p-value $>0.05$ in level of ferritin among cases between different family history and course of disease; which indicates no effect of these variables on ferritin level among cases.

\begin{tabular}{|c|c|c|c|c|}
\hline \multirow{2}{*}{$\begin{array}{c}\text { Variables } \\
(\mathrm{n}=)\end{array}$} & \multicolumn{2}{|c|}{ Ferritin level (ng/ml) } & \multirow{2}{*}{ p-value } & Sig. \\
\cline { 2 - 3 } & Mean & SD & \\
\hline Family history & 71.2 & 107.9 & \multirow{2}{*}{0.8} & NS \\
\hline Negative & 79.6 & 46.2 & & \\
\hline Positive & 87.4 & 128.2 & \multirow{2}{*}{0.6} & NS \\
\hline Course of disease & 69.9 & 41.4 & & \\
\hline \multicolumn{2}{|c|}{ Stationary } & &
\end{tabular}

Table (3): Comparisons of serum ferritin in different disease characters among cases.

4. There was no statistically significant difference in serum vitamin D level between patients with positive family history and patients with negative family history with $\mathrm{p}$ value $=0.4$. Also there was no significant difference in serum vitamin D level between patients who have a progressive course and 
those who had stationary course which indicates no correlation between vitamin d level and course of disease.

\begin{tabular}{|c|c|c|c|c|}
\hline \multirow{2}{*}{$\begin{array}{l}\text { Variables } \\
(\mathrm{n}=30)\end{array}$} & \multicolumn{2}{|c|}{$\begin{array}{l}\text { Vitamin D level } \\
(\mathrm{ng} / \mathrm{ml})\end{array}$} & \multirow{2}{*}{ p-value } & \multirow{2}{*}{ Sig. } \\
\hline & Mean & SD & & \\
\hline \multicolumn{5}{|l|}{ Family history } \\
\hline Negative & 32.5 & 11.8 & \multirow{2}{*}{0.4} & \multirow{2}{*}{$\mathrm{Ns}$} \\
\hline Positive & 41.2 & 10.7 & & \\
\hline \multicolumn{5}{|c|}{ Course of disease } \\
\hline Stationary & 34.1 & 8.1 & \multirow{2}{*}{0.3} & \multirow{2}{*}{ NS } \\
\hline Progressive & 38.6 & 13.3 & & \\
\hline
\end{tabular}

Table (4): Comparisons of vitamin D in different disease characters among cases.

5. There was no statistically significant correlation with p-value $>0.05$ between ferritin level and age, disease duration and grades of hair loss. This indicates that no correlation between serum ferritin level and age of patients, no correlation between ferritin level and disease duration and also no correlation between serum ferritin level and grade of hair loss. Similarly there was no significant correlation between serum vitamin $\mathrm{D}$ and disease characters.

\begin{tabular}{|l|c|c|c|c|}
\hline \multirow{2}{*}{\multicolumn{1}{|c|}{ Variables }} & \multicolumn{2}{|c|}{ Serum Ferritin } & \multicolumn{2}{c|}{ Vitamin D } \\
\cline { 2 - 5 } Age (years) & r & p-value & r & p-value \\
\hline Disease duration (years) & -0.08 & 0.7 & 0.04 & 0.8 \\
\hline Grade of hair loss & -0.21 & 0.3 & 0.12 & 0.5 \\
\hline Vitamin D & -0.24 & 0.2 & 0.06 & 0.8 \\
\hline
\end{tabular}

Table (5): among Correlation between ferritin level and vitamin D and disease characters cases. 


\section{Discussion:}

There are several postulated mechanisms by which both iron and vitamin $\mathrm{D}$ have possible effects on hair growth. As for the role of iron, The most widely cited nutritional causes of hair loss include iron, one of the key micronutrients in metabolism of our body. From its diverse functions, it is well known that iron deficiency is associated with a lot of pathological conditions, however, its role in hair loss is not well established yet [2].

It has been suggested that an optimal concentration of vitamin $\mathrm{D}$ is necessary to delay aging phenomena, including hair loss; this might explain the importance of vitamin D in the hair. Moreover, extensive data from animal models clearly show that vitamin D receptor activation plays an important role in the hair follicle cycle, specifically anagen initiation [7].

Furthermore, data suggested that vitamin D receptor directly or indirectly regulates the expression of genes required for hair follicle cycling [9].

Several studies were done to evaluate the role of vitamin $\mathrm{D}$ in different hair disorders with contrasting results. Some studies revealed low serum levels of vitamin D in women with chronic telogen effluvium, female pattern hair loss and alopecia areata. [4] and [10]. While, two studies showed no correlation between the extent and severity of male androgenetic alopecia with serum vitamin D level [11] and [12].
Based on the above contrasting reports, we sought to evaluate the levels of ferritin and vitamin D in male patients with androgenetic alopecia in order to establish its possible role in the etiopathogenesis and hence in the treatment of such a common and chronic hair disorder.

In this study, we found no statistically significant difference between cases and control groups as regard serum ferritin level. Our results agree with Sinclair, 2002 [13] who reported no significant difference in ferritin level between cases and control in females with hair loss.

The study results are also in agreement with Bregy and Trueb, 2008 [5] who measured serum ferritin level in 181 otherwise healthy women with female pattern hair loss and/or telogen effluvium and concluded that no association between serum ferritin levels and hair loss activity in women.

On the other hand, the study results disagree with Park et al., 2013 [2], who did a retrospective chart review on patients with hair loss and found that serum ferritin level was significantly lower in patients with male pattern hair loss and female pattern hair loss than that in control.

The study results disagree also with Rasheed et al., 2013 [4] who did a case control study and found significantly lower levels of serum ferritin in female patients with androgenetic alopecia compared to control. 
The study results also disagree with Kantor et al., 2003 [14] who did analytical cross-sectional study to evaluate whether common types of alopecia in women are associated with decreased tissue iron stores, as measured by serum ferritin. They found that the mean ferritin level in patients with androgenetic alopecia and alopecia areata were statistically significantly low.

There is no clear explanation of this discrepancy and additional work is definitely needed to resolve this scientific debate. The existence of several variables, e.g. the study designs adopted in different studies, the variability of the definition of a normal serum ferritin level and the different reference ranges used by different laboratories, are some factors that could contribute in this detected discrepancy [15].

In this study, serum vitamin D level was significantly lower in cases than control. These results are in agreement with Rasheed et al., 2013 [4] and Banihashemi et al., 2016 [10] who found vitamin D level significantly lower in patients with female pattern hair loss than that in control.

The study results agree also with Moneib et al., 2014 [16] who did a case control study to measure vitamin D level in in 60 patient with female pattern hair loss compared to 60 age matched control. They found vitamin D level was significantly lower in cases than that in control

In the current study, we found no correlation between vitamin $\mathrm{D}$ level and degree of hair loss. These results are in agreement with Bolland et al., 2008 [11] and Iyanda, 2012 [12] who found that the degree of baldness does not appear to influence serum vitamin D levels in patients with male pattern hair loss.

On the contrary, the study results disagree with Rasheed et al., 2013 [4] who found that serum vitamin D 2 level was correlated with the degree of hair loss in patient with female pattern hair loss. This may be attributed to difference in study design as our study was done in male pattern.

The study results disagree also with Moneib et al., 2014 [16] who found that serum vitamin D level was correlated to the degree of alopecia in female patients with androgenetic alopecia.

\section{Conclusion:}

In conclusion; vitamin D level was significantly lower in patients with male pattern hair loss than that in control. Serum ferritin level was lower in patients with male pattern hair loss than that in control but it was statistically insignificant.

\section{References:}

[1] Tang PH, Chia HP, Cheong LL, Koh D. (2000): A community study of male androgenetic alopecia in Bishan, Singapore. Singapore medical journal; 41:202-205 
[2] Park SY., Na SY., Kim J.Het al. (2013): Iron plays a certain role in patterned hair loss. Journal of Korean medical science, 28(6), 934-938.

[3] Finner AM (2013): Nutrition and hair: deficiencies and supplements Dermatol Clin.:(1):167-72.

[4] Rasheed H, Mahgoub D, Hegazy R, El-Komy M, et al. (2013): Serum ferritin and vitamin $d$ in female hair loss: do they play a role? Skin Pharmacol Physiol. ;26:101-7.

[5] Bregy A, Trueb RM. (2008) : No association between serum ferritin levels $>10$ microg/l and hair loss activity in women; Dermatology.;(1):1-6

[6] Amor KT, Rashid RM, Mirmirani P. (2010): Does D matter? The role of vitamin D in hair disorders and hair follicle cycling. Dermatol Online J. ;16:3.

[7] Bouillon R, Carmeliet G, Verlinden L, van et al. (2008): Vitamin D and human health: lessons from vitamin D receptor null mice. Endocr Rev; 29: 726-776.

[8] Zheng Y, Prouty SM, Harmon A, et al. (2001): Scd3 - a novel gene of the stearoyl-CoA desaturase family with restricted expression in skin. Genomics; 71: 182-191.

[9] Demay MB (2012): The hair cycle and vitamin D re-ceptor. Arch Biochem Biophys; 523: 19-21.
[10] Banihashemi, M.; Nahidi, Y.; Meibodi, et al. (2016): Serum Vitamin D3 Level in Patients with Female Pattern Hair Loss.Int. J. Trichol.,8, 116-120.

[11]Bolland MJ, Ames RW, Grey AB et al. (2008): Does degree of baldness influence vitamin D status? Med J Aust;189(11-12):674-5.

[12] Iyanda AA. (2012): Serum vitamin levels in different categories of androgenetic alopecia subjects. Sci Rep.;1:137.

[13] Sinclair R. (2002): There is no clear association between low serum ferritin and chronic diffuse telogen hair loss. Br J Dermatol. ;147:982-984.

[14] Kantor J, Kessler LJ, Brooks DG, Cotsarelis G. (2003): Decreased serum ferritin is associated with alopecia in women. J Invest Dermatol. ;121:985-8.

[15] Oslen EA, Reed KB, Cacchio PB, Caudil L. (2010): Iron deficiency in female pattern hair loss, chronic telogen effluvium, and control groups. J Am AcadDermatol.; 63:991-9

[16]Moneib, H.; Fathy, G.; Ouda, A. (2014): Possible association of female-pattern hair loss with alteration in serum 25-hydroxyvitamin D levels.Egypt. J. Dermatol. Venerol.,34, 15-20. 